\title{
Critical Design Factors on Performance of Car Jack Lifting
} Operations

\author{
Dzul Hafez Yacob, S. Sarip, M. A. Suhot, M. Z. Hassan, S. A. Aziz, M. Y. Daud, \\ N. A. Bani, M. N. Muhtazaruddin \\ Razak School of Engineering and Advanced Technology, Universiti Teknologi Malaysia, \\ Jalan Sultan Yahya Petra, 54100 Kuala Lumpur, Malaysia
}

\section{Article Info}

Article history:

Received Jun 30, 2018

Revised Aug 1, 2018

Accepted Aug 10, 2018

\section{keywords:}

Car jack

Design analysis

Design failure mode and effects

analysis

Design modeling

Failure root cause analysis

\begin{abstract}
Car jack is an equipped accessory package in every units of car sold to customer that used to uplift the cars while replacing tires during an emergency or repair. The automotive manufacturers are actively conducting their Product Improvement Campaign and the objective of the campaign is to improve the quality of product sold to the customers. The current jack design has a possibility of failure during its operations. The customer satisfaction point of view will be converted to engineering characteristic to acquire the concept of design and input into new design proposal and at the same time eliminate the possibility of failure of the current design. The research is conducted to improve the current jack design on its performance in lifting operations. The scope of research is to identify the critical zone in jack design structure that possibly causing the failure during its operations. To optimize the existing design, it is proposed some modification on the jack structure with a minimum weight increment but improve the design structural strength. The failure root cause analysis, reliability test and Design Failure Mode and Effect Analysis have been used to identify the specific critical area in the structure and resolve them by proposing the new improved jack design. The current car jack sample in market is used as an industrial sample for design analysis to find the target area for further improvement. From the analysis, we can know the critical design factors in the current car jack design and the required design improvement to enhance its performance in lifting operations.
\end{abstract}

Copyright $\odot 2018$ Institute of Advanced Engineering and Science. All rights reserved.

\section{Corresponding Author:}

Dzul Hafez Yacob,

Razak School of Engineering and Advanced Technology,

Universiti Teknologi Malaysia,

Jalan Sultan Yahya Petra, 54100 Kuala Lumpur, Malaysia.

Email: hafedzul@gmail.com

\section{INTRODUCTION}

An automotive jack is a device used to raise all or part of a vehicle into the air in order to facilitate repairs and changing tires. Most people are familiar with the basic automotive jack that was still included as standard equipment equipped in every new car. It is an obligation to the manufacturer to ensure customer safety while handling the jack operations. The automotive manufacturer keeps conducting their product improvement campaign and the objective of this campaign is to improve their product quality especially the current car jack which has a possibility of collapse during its operations.

The main aim of the study is to identify the critical areas in current car jack design that lead to the failure during operations. The current jack design will be transformed into 3D model and undergone with design analysis. From the design analysis result, the new car jack design can be proposed at the end of the research. 
The research has fixed its focal points where the specific area of improvement in the car jack structure is at the lower and upper arm gear area. There are a few types of analysis will be used in the research such as reliability test on the actual current jack sample, to identify the actual root cause of the jack failure from the actual defective sample in market, Design Failure Modes and Effects Analysis (DFMEA) to identify the potential cause of failure and the design analysis that focus on stress, strain and deformation characteristic of the jack structure. The research used the SOLIDWORKS software for modelling and ANSYS for design analysis.

\section{RESEARCH METHOD}

The research begins with collecting defective sample from market for failure root cause analysis [1]. The fresh part of the same car jack model is prepared for reliability tests. The purpose of reliability test is to check the durability of current jack model whether can withstand with the industrial requirement and to replicate the failure condition happened in market [2]. Design Failure Mode and Effects Analysis (DFMEA) is used to identify the potential failure modes and the cause of failure during jack lifting operations [3]. From the result, it will give a directive improvement to the current design. Modeling of the current and new improved design are developed for design analysis purposes [4]. Both designs will be performed with three types of analysis such as Equivalent Elastic Strain (von-Mises), Equivalent Stress (von-Mises) and Total Deformation to measure the design performance [5]. Additional analysis to measure stress value at the improvement area to verify the effectiveness of the design improvement [6]. All results obtained is gathered in a comparison table and discussed.

For design analysis, certain parameters have been set for both current and new jack design. The parameters set in the analysis are the lifting height of both design is set at $320 \mathrm{~mm}$ off ground, the material used to build the jack is Hot Rolled Steel Sheet (SPHC) JIS G3131 with Tensile Strength of $270 \mathrm{MPa}$, the applied load on the jack design is set at $21,575 \mathrm{~N}$, the outer dimension of both designs are same and the selected structural analysis type used are the elastic strain, stress and total deformation.

\section{RESULTS AND ANALYSIS}

The research process is characterized by five elements. The characterized elements are the jack failure root cause analysis on the actual defective samples collected from market, reliability test on fresh part, car jack potential failure modes using Design Failure Mode and Effects Analysis (DFMEA) tool, jack modeling and design analysis. Results of these five elements are presented in this section.

\subsection{Car Jack Failure Root Cause Analysis}

The first activity of the research methodology is by obtaining the defective jack from market. A few defective samples were collected from market and dismantled to observe the deformation characteristic. The root cause of the failure obviously can be seen at gearing area that causing the jack to fail during its operations. The defects check on the defective sample exhibited from market is shown in Figure 1.

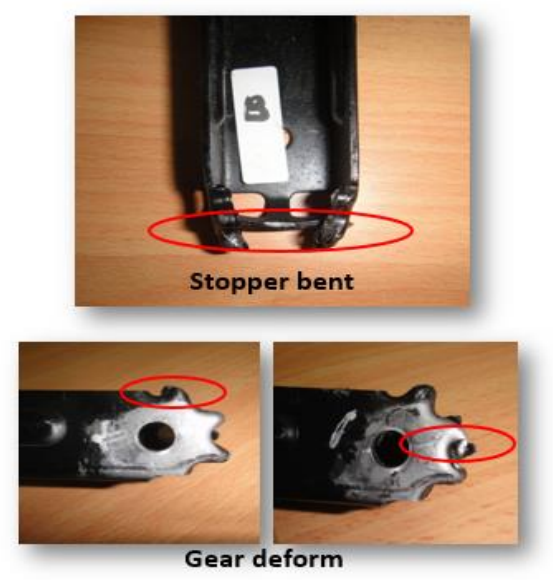

Figure 1. Actual defective sample collected from market 


\subsection{Reliability Test}

Fresh part of the current jack design is collected and assigned for specific test. This activity purposely to replicate the failure happened in market in order to understand how and why the incident occurs. The reliability tests conducted are inclined load test, load endurance test, strength intensity load test and Monkey "shaken" test. From the reliability result, the only NG (Fail) result is on the Monkey test. The jack is lifted at height of $320 \mathrm{~mm}$ off ground with full laden load and shaken to magnify the free play condition at this height of the current jack structure. The end result shows that at this height the contact between gears is very poor and allow the gears to slip and cause the collapse.

\subsection{Design Failure Mode and Effects Analysis}

The Design Failure Mode and Effects Analysis was conducted to identify the potential root cause of the jack failure. There are few potential failure modes identified that can cause the failure to happen. From the analysis, the top 4 highest Risk Priority Numbers (RPN) obtained from the analysis said that the jack failure is caused by the following 4 potential causes of failure:

a. Insufficient gear engagement, jack components failure, excessive load applied

b. Misalignment of jack with vehicle body frame, operation done on uneven road

c. User mislead with the safety pre-caution procedure during jack operation

d. Difficulty of aligning the vehicle body frame to slot into top bracket groove (arm stay). The misaligned flange sitting onto arm stay may cause the imbalance load point during operation of jack.

Item (a) and (d) are design related issues that can be a target area for design improvement on existing car jack. The earlier result of investigation and tests have shown that the possible design improvement can be done at gearing area for better engagement and arm stay slot's opening for easier insertion of vehicle body frame to prevent imbalance load point. The new improved design of jack is realized based on the improvement guideline from the investigation and test results. The new car jack design has been proposed with a modification at arm stay, upper and lower arm gear.

The overall investigation and analysis finding to identify the root cause of failure is shown in Table 1. From the results, it gives a directive design improvement that can be implemented on the current design. The new improved design consists of additional parts and modification of existing component such as it separates the gearing components for upper and lower arm body to strengthen the gearing system, the arm stay part is modified to have a chamfering at the slot opening and the upper and lower arm design are common parts with reduction of some materials to remain its total weight even though there is an additional of four gear plates in the structure. The design improvement done on the current jack design is shown in Figure 2.

Table 1. Failure Root Cause Analysis

\begin{tabular}{lll}
\hline \multicolumn{1}{c}{ Type of Analysis } & & \multicolumn{1}{c}{ Results } \\
\hline Defective sample observation and Root & - & Severe damage at gearing area \\
cause analysis & - & The gear skewed-in for both LH and RH \\
& - & Collapse due to poor contact of gears \\
Reliability test & - & Four (4) types of test are performed \\
& - & Result NG for Monkey (shaken) test for full laden load at 320mm off-ground \\
& - & The result replicates same condition of gearing problem \\
Design Failure Mode and Effects & - & Top four (4) highest RPN of Potential cause of failure are: \\
Analysis (DFMEA) & - Insufficient gear engagement, jack component failure, excessive load applied \\
& - Jack operation on uneven road, misalignment with vehicle body frame \\
& - Wrong procedure of jack lifting operation \\
& - & Imbalance load point on the jack \\
\hline
\end{tabular}

\subsection{Design Modeling}

The overall investigation and analysis finding to identify the root cause of failure is shown in Table 1. From the results, it gives a directive design improvement that can be implemented on the current design. The new improved design consists of additional parts and modification of existing component such as it separates the gearing components for upper and lower arm body to strengthen the gearing system, the arm stay part is modified to have a chamfering at the slot opening and the upper and lower arm design are common parts with reduction of some materials to remain its total weight even though there is an additional of four gear plates in the structure. The design improvement done on the current jack design is shown in Figure 2. 


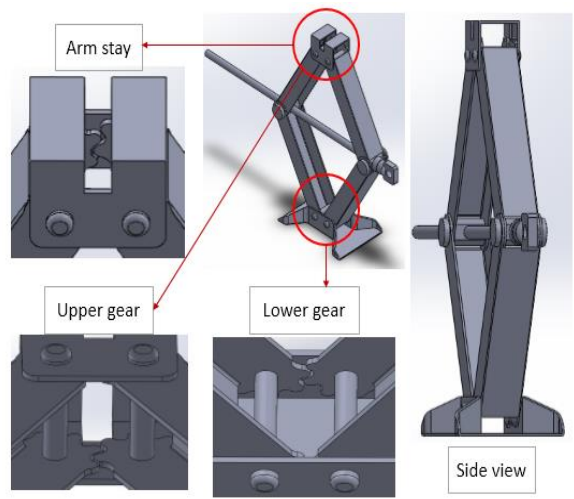

Current Design

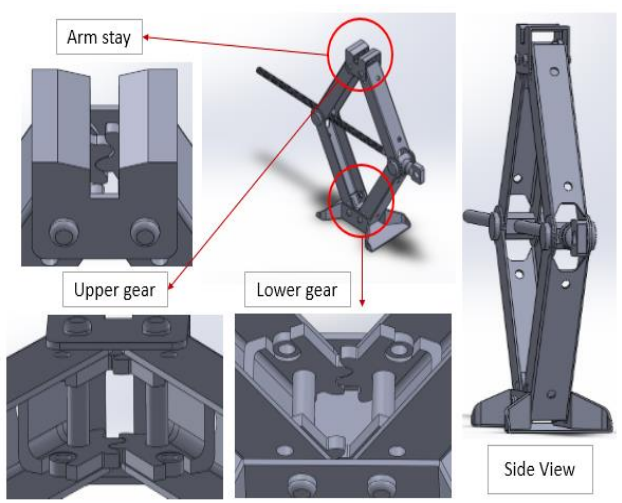

New Design

Figure 2. Design improvement on current jack design

\subsection{Design Analysis}

Three types of analysis have been performed onto the current and new jack design such as Equivalent Elastic Strain (von-Mises), Equivalent Stress (von-Mises) and Total deformation to measure the design performance.

The equivalent elastic strain analysis of the whole jack structure for both, current and new jack design in graphical comparison is shown in Figure 3. Based on the plotted graph, the maximum value of elastic strain for current jack design is $2.75 \times 10-3$ and the new jack design is $2.29 \times 10-3$. The new jack design has decrease the strain value by $16.9 \%$. The maximum strain value for the current design occurs at lower arm part and the new design is at upper gear.

The equivalent stress analysis of the whole jack structure for both, current and new jack design in graphical comparison is shown in Figure 4. Based on the plotted graph, the maximum value of stress for current jack design is $5.41 \times 108 \mathrm{~Pa}$ and the new jack design is $4.42 \times 108 \mathrm{~Pa}$. The new jack design has decrease the stress value by $18.14 \%$. The maximum stress value for the current design occurs at upper arm and the new design is at upper gear.

The total deformation analysis of the whole jack structure for both, current and new jack design in graphical comparison is shown in Figure 5. Based on the plotted graph, the maximum value of total deformation for current jack design is $3.37 \times 10-4 \mathrm{~m}$ and the new jack design is $3.01 \times 10-4 \mathrm{~m}$. The new jack design has decreased the stress value by $10.5 \%$. The maximum total deformation value for both current and new jack design occurs at arm stay.

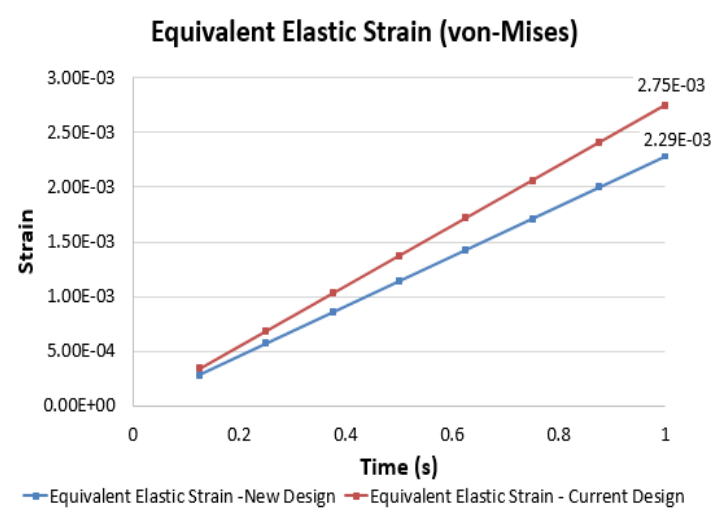

Figure 3. Graph of comparison for elastic strain

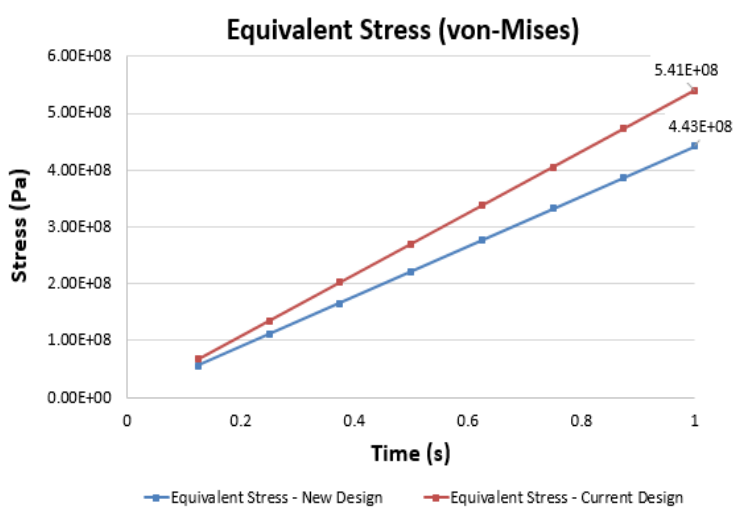

Figure 4. Graph of comparison for stress value 


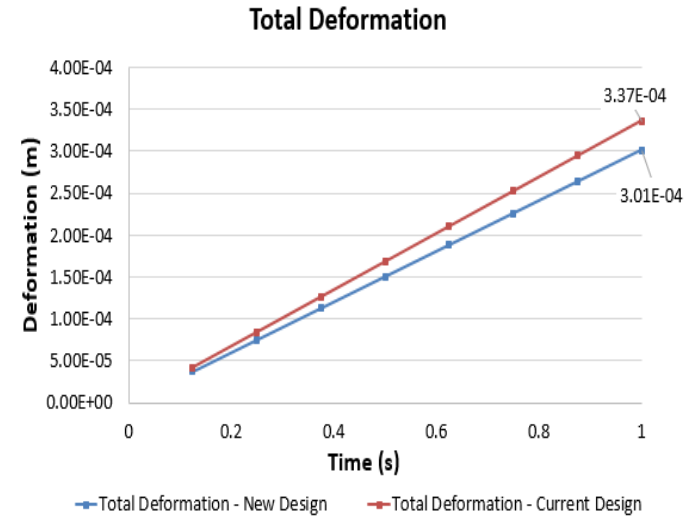

Figure 5. Graph of comparison for total deformation

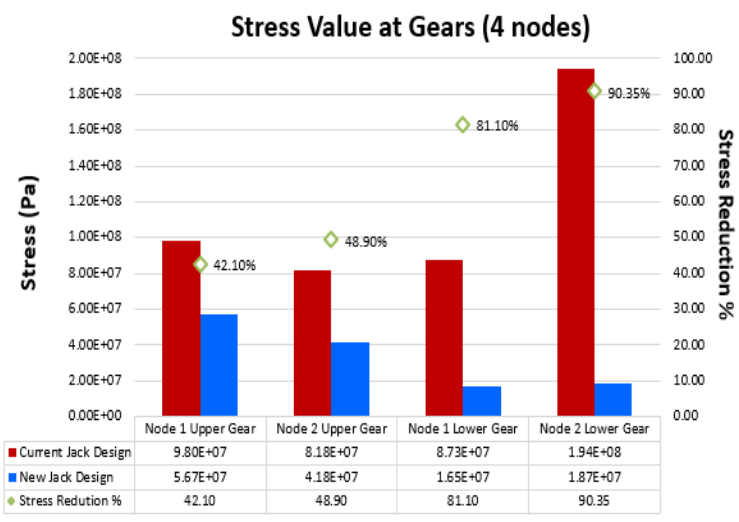

Figure 6. Graph of comparison for stress value at gears

The gearing area is identified as the critical area in jack structure that has to undergo with design modification to eliminate the possibility of failure during jack lifting operation. Since that, in design analysis there are four nodes purposely placed at gearing area for both, current and new jack design to observe the stress value. The graphical comparison of the stress value at gearing area is shown in Figure 6. From the comparison of those 4 nodes' stress value, the stress reduction at Node 1 Upper Gear is given by $42.1 \%$, at Node 2 Upper Gear by $48.9 \%$, at Node 1 Lower Gear by $81.1 \%$ and at Node 2 Lower Gear by $90.35 \%$.

The overall result comparison between old and new jack assembly design analysis is shown in Table 2. Design analysis results show that the new jack design has resolved the problem encountered in current jack design and the improvement can be seen through the stress, strain and total deformation chart plotted for comparison of both designs.

The total weight of both jack designs is automatically measured by the design analysis software. From the geometry properties displayed in the software, the total weight of current jack design is $1.9279 \mathrm{~kg}$ and the new jack design is $2.1828 \mathrm{~kg}$. The weight difference between both designs is $254.9 \mathrm{~g}$. The weight increment is due to the additional 4 gear plates to strengthen the design structure.

Table 2. Overall Analysis Results

\begin{tabular}{|c|c|c|c|c|}
\hline \multicolumn{2}{|c|}{ Characteristics } & Current Design & New Design & Reduction Percentage $(\%)$ \\
\hline \multicolumn{2}{|c|}{ Max. Equivalent Elastic Strain (von-Mises) } & $2.7506 \times 10^{-3}$ & $2.2855 \times 10^{-3}$ & $16.9 \%$ \\
\hline \multicolumn{2}{|c|}{ Max. Equivalent Stress (von-Mises) } & $5.4073 \times 10^{8} \mathrm{~Pa}$ & $4.4262 \times 10^{8} \mathrm{~Pa}$ & $18.14 \%$ \\
\hline \multicolumn{2}{|c|}{ Max. Total Deformation } & $3.3661 \times 10^{-4} \mathrm{~m}$ & $3.013 \times 10^{-4} \mathrm{~m}$ & $10.5 \%$ \\
\hline \multirow{4}{*}{$\begin{array}{l}\text { Stress Value at } \\
\text { Gears }\end{array}$} & Node 1 Upper gear & $9.80 \times 10^{7} \mathrm{~Pa}$ & $5.67 \times 10^{7} \mathrm{~Pa}$ & $42.14 \%$ \\
\hline & Node 2 Upper gear & $8.18 \times 10^{7} \mathrm{~Pa}$ & $4.18 \times 10^{7} \mathrm{~Pa}$ & $48.9 \%$ \\
\hline & Node 1 Lower gear & $8.73 \times 10^{7} \mathrm{~Pa}$ & $1.65 \times 10^{7} \mathrm{~Pa}$ & $81.1 \%$ \\
\hline & Node 2 Lower gear & $1.94 \times 10^{8} \mathrm{~Pa}$ & $1.87 \times 10^{7} \mathrm{~Pa}$ & $90.35 \%$ \\
\hline
\end{tabular}

\section{CONCLUSION}

The result of investigation and analysis has given an idea of where is the specific area that contributes much to the failure. After further understanding of the actual root cause of the failure, then design modification stage can be performed accurately. The new jack design has improved in a few things such as its gearing system, the chamfering at slot opening of the arm stay and the aesthetic aspect of the structural design. In overall, the new proposed design has improved the strain, stress and total deformation properties of the car jack structure compared to the current design. The overall improvement (reduction of value) can be given as, Equivalent Elastic Strain (16.9\%), Equivalent Stress (18.14\%) and total deformation $(10.5 \%)$. The modification of the gear design and the gear thickness (from $2 \mathrm{~mm}$ to $4 \mathrm{~mm}$ ) significantly affects the stress and strain distribution in the jack structure.

\section{REFERENCES}

[1] Dhamak, B., Aher \& Nikam, "Design and Standardization of Scissor Jack to Avoid Field Failure". Internation Journal Of Advance Research And Innovative Ideas In Education. 2015; Volume 1 Issue 3. 
[2] Ipilakyaa T.D., A.V.T., Gbashi S., "Design, Construction and Testing of an Electric Powered Toggle Jack Mechanism". International Research Journal of Engineering and Technology. 2017; Volume: 04 Issue: 02.

[3] Kolich, M., "Using Failure Mode and Effects Analysis to design a comfortable automotive driver seat". Applied Ergonomics, 2014; 45(4): p. 1087-1096.

[4] Patil, M.R. and S. Kachave, "Design And Analysis Of Scissor Jack". International Journal of Mechanical Engineering and Robotics Research, 2015. 4(1): p. 327.

[5] Kachave, M.R.P.a.S.D., "Design and Analysis of Scissor Jack". International Journal of Mechanical Engineering and Robotics Research. 2015; Vol. 4: No. 1.

[6] Chitransh, J. and D. Hussain, "Designing And Calculating The Stresses Induced In Scissors Jack For Three Different Materials". International Journal Of Scientific \& Technology Research. 2016; Volume 5: Issue 07. 